\title{
The Efficacy of Using Lidocaine Jelly 2\% for Prevention of Inadvertent Retrograde Stone Displacement during Pneumatic Lithotripsy of Upper Ureteral Stone
}

\author{
Saad H. Al-Sammarraie ${ }^{1}$, Ala'a Al-Deen AL-Dabbagh ${ }^{2}$, Sahar B. Ahmed ${ }^{3}$ \\ ${ }^{1}$ Consultant urologist, Al-Yarmouk Teaching Hospital /Department of Urology/Baghdad/IRAQ \\ ${ }^{2}$ Assistant Professor, Al-Mustansiriya university/college of medicine/Department of surgery/Baghdad/IRAQ \\ ${ }^{3}$ Radiology Spesicialist, Al-Yarmouk Teaching Hospital/Departmwnt of Radiology/Baghdad/IRAQ
}

\begin{abstract}
Aim:to assess the efficacy of lidocaine jelly instillation proximal to the upper ureteral stone during intracorporial pneumatic lithotripsy using semirigiduretroscope for the prevention of retrograde migration and improvement in stone free rate. Forty patients with upper ureteric stone were studied in Al-Yarmouk Teaching Hospital /Baghdad/Iraq during the period from February 2015 to December 2015. Patients were randomly divided into two equal groups, group (A) patients were undergone pneumatic lithotripsy using lidocaine jelly $2 \%$ proximal to the ureteric stone. Group (B) patients underwent the pneumatic lithotripsy without using lidocaine jelly. A $5 F r$ double $J$ was left in place for 4 weeks \& patients were followed up with ultrasound \& CT for abdomen \& pelvis. It was found that the 2 groups were comparable with regard to age \& stone size. Stone or its fragment migration occurred in $5 \%$ \& $30 \%$ of patients in group $A$ $\& B$ respectively, a significant difference $P=0.0382$. At 4 weeks follow up with imaging, the stone free rate was $95 \%$ \& $65 \%$ in group $A \&$ $B$ respectively. This difference was also statistically significant $(p=0.01711)$. Although the mean operative time was slightly longer in the group $A$ (42 \pm 10 minutes) than in group $B(40 \pm 10$ minutes $)$, the difference was not significant $(p=0.361)$. We concluded that lidocaine jelly instillation proximal to ueretral calculi during pneumatic lithotripsy is an effective method of preventing retrograde stone displacement as well as significantly improving the stone free rate.
\end{abstract}

Keywords: upper ureteric stone, ureteroscope, pneumatic lithotripsy, lidocaine jelly, stone migration

\section{Introduction}

Between $5-12 \%$ of the population will have a urinary tract stone during their lifetime, and recurrence rates approach $50 \%$. The peak incidence of lithiasis appears to be between the ages of 45-64 years. Males have more than twice the rate of stone formation than females ${ }^{[1]}$.

The stone that obstructs a patient's ureter originates in the kidney. Ureteric colic occurs as a result of obstruction of the urinary tract by calculi at the narrowest anatomical areas of the ureter: the pelviureteric junction (PUJ), near the pelvic brim at the crossing of the iliac vessels and the narrowest area, the vesicoureteric junction (VUJ) ${ }^{[2]}$.

Treatment options of ureteric stone include watchful waiting, medical expulsive therapy, ESWL, ureteroscopy, open ureterolithotomy \& laparoscopic ureterolithotomy. Intracorporeal lithotripsy through uretroscopy has emerged as treatment of choice for ureteric stone ${ }^{[3]}$.With development of small caliber semirigid and flexible uretroscopies and the introduction of improved instrumentation, it has evolved into a safer and more efficacious modality for treatment of stones in all locations in the ureter \& with increasing experience, worldwide complication rates, most notably ureteral perforation rates, have been reduced to less than $5 \%$, and long- term complications such as stricture formation occur with incidence of $2 \%$ or less ${ }^{[4]}$.
Parallel to improvements of rigid and flexible uretroscopies , there were advancement in intracorporeal lithotripters, including ultrasonic, electrohydrolic, pneumatic and laser lithotripters ,allowing efficient stone fragmentation through the modern ureteroscopic equipments ${ }^{[5]}$.

There are many of stone - retrieved devices; the baskets that are most commonly used, flat-wire basket, and nitinol-tip basket $^{[6]}$.

Retrograde calculus migration during ureteroscopic procedures remains a significant problem. Clinical studies have reported an incidence of $40-50 \%$ for ureteral stone migration from the proximal ureter, and $5-10 \%$ for migration from the distal ureter [7].

The risk of proximal fragment migration is influenced by the pressure of the irrigant fluid, type of energy source used for intracorporeal lithotripsy, site and degree of calculus impaction, and degree of proximal ureteral dilatation ${ }^{[8]}$.

Pneumatic and electrohydraulic lithotrites cause more retrograde propulsion of the ureteral stones than holmium: YAG laser and ultrasonic lithotrites.

Proximal stone migration is more likely with smaller stones, and greater proximal ureteral dilation or hydronephrosis ${ }^{[9]}$. Retrograde stone migration results in a longer operating time, more invasive endoscopy, and an increase in residual 


\section{International Journal of Science and Research (IJSR) \\ ISSN (Online): 2319-7064 \\ Index Copernicus Value (2013): 6.14 | Impact Factor (2015): 6.391}

stones and the need for secondary procedures, leading to higher morbidity, and greater expense.

To prevent stone migration, surgeons have traditionally used a number of maneuvers, including reverse Trendelenburg position, to optimize the effects of gravity and decreased irrigation pressure and flow rate ${ }^{[10]}$.

Numerous devices have been employed to reduce the incidence of proximal stone migration during ureteroscopy including the use of ureteralbaskets, Lithocatch, Lithovac, passport balloon, parachute, entrapment net (N Trap), Accordion, BackStop and the Stone Cone ${ }^{[11]}$.

This study was designed to ascertain the efficacy of lidocaine jelly $2 \%$ instillation proximal to the upper ureteral stone during intracorporeal pneumatic lithotripsy using a semirigiduretero scope for the prevention of retrograde migration and improvement in stone-free rate.

\section{Patients \& Methods}

From February 2015 to December 2015 , 40 patients(28 males, 12 females), with upper ureteral stones (6-12 $\mathrm{mm})$ were admitted to Al-Yarmok Teaching Hospital, urology unit, and enrolled in this study, their age ranged from (1860 )years, with a mean age of 35 years.

All patients were evaluated by history taking, physical examination, laboratory investigations, including: (urinalysis, full blood count, and renal function test).

Preoperative radiographic imaging studies including; KUB, ultrasound, and computerized tomography (CT) scan. From which stone size, location, opacity, and degree of obstruction were assessed.

Exclusion criteriaincluded the presence of any degree of ureteral stricture distal to the stone, stone impaction, clinical evidence of sepsis, coexistence of a kidney stone, lower ureteric stone\&small stones retrieved by grasper

The patients were selected on the basis of standard indications for intervention for ureteric stone. Patients were randomized.Into 2 equal groups. Group A (using lidocaine gel) and group B (without using lidocaine gel) .The operations were done under general anesthesia.All patientsreceived a single dose of broad spectrum antibiotics parenterally at timeof induction anesthesia.

The 20 patients in the Group A receivedlidocaine $2 \%$ jelly instillation before intracorporeal lithotripsy using pneumatic lithotripsy (Swiss LithoClast), and the 20 patients in the control group (group B) were treated with a conventional method without jelly.

All patients underwent ureteroscopy under general anesthesia using 9.5Fr. semirigidureteroscope with $5 \mathrm{Fr}$. working channel\& 6 degree lens.

Patients were placed in standard lithotomy position, theureteroscope waspassed in to the ureter with the aid of 0.035 inch guide wire in most of our patients without a need for ureteral dilation.After placing the guide wire and reaching the stone with the semirigidureteroscope, an open end ureteral catheter ( 5 Fr.) was advanced through the working channel, until it reached beyond the stone, and $2 \mathrm{ml}$ of $2 \%$ lidocaine jelly was instilled in the ureteral lumen proximal to the stone using a $5 \mathrm{ml}$ syringe then the ureteral catheter was withdrawn, and the probe of the pneumatic Lithoclast was advanced through the working channel to start the process of stone fragmentation with single shot fragmentation. Continuous low - pressure fluid flow was necessary to maintain visibility of stone.

The stone fragments were removed by stone grasper and the remaining amount of lidocaine jelly was washed out with saline irrigation. A 5 Fr double J stent was inserted over the guide wire, and left indwelling for four weeks.

The procedure was considered successful in either group if no proximal stone migration occurred, and if the stone was fragmented completely.

Foley's catheter was inserted in all of our patients and was removed on the next day, except in cases of hematuria, it remained for longer time.

Parenteral antibiotics were continued for two days and replaced by oral antibiotics for 5-7 days.

KUB was taken on the same or next day. Most of our patients were discharged on first post -operative day, and returned back after four weeks for follow-up with ultrasound and CT scan for abdomen and pelvis and for removal of the double J stent using 22 FrStorzcystoscope.

\section{Results}

A total of 40 patients (28 males and 12 females) were treated by semirigidureteroscopy and pneumatic lithotripter for upper ureteric stone. Their age ranged from 18-60 years with a mean age of 35 years. They were divided into 2 equal groups (group A) and (group B). The 2 groups were comparable with regard to age and stone sizeas shown in tables $1 \& 2$

Table 1: distribution of gender according to age

\begin{tabular}{|c|c|c|}
\hline Stone size & Group A & Group B \\
\hline $6 \mathrm{~mm}$ & 5 & 4 \\
\hline $7 \mathrm{~mm}$ & 3 & 3 \\
\hline $8 \mathrm{~mm}$ & 4 & 5 \\
\hline $9 \mathrm{~mm}$ & 3 & 2 \\
\hline $10 \mathrm{~mm}$ & 3 & 3 \\
\hline $12 \mathrm{~mm}$ & 2 & 3 \\
\hline
\end{tabular}




\section{International Journal of Science and Research (IJSR) \\ ISSN (Online): 2319-7064 \\ Index Copernicus Value (2013): 6.14 | Impact Factor (2015): 6.391}

Table 2: Distribution of group A \& B according to stone size

\begin{tabular}{|c|c|c|}
\hline Agegrouplyans & male & fente \\
\hline $18 y$ & 2 & 0 \\
\hline $24 y$ & 3 & 2 \\
\hline $28 y$ & 2 & 1 \\
\hline $35 y$ & 8 & 5 \\
\hline $38 y$ & 4 & 2 \\
\hline $45 y$ & 4 & 1 \\
\hline $58 y$ & 3 & 1 \\
\hline $60 y$ & 2 & 0 \\
\hline & $28(66.6 \%)$ & $12(333.3 \%)$ \\
\hline
\end{tabular}

The state of the renal dilatation showed normal pelvicalyceal system in 8 patients $(20 \%)$, mild hydronephrosis in 20 patients $(50 \%)$, moderate hydronephrosis in 10 patients $(25 \%)$ and severe hydronephrosis in 2 patients $(5 \%)$.

Upward stone or fragment migration to the kidney occurred in only one patient $(5 \%)$ in the (group A) due to the severe hydronephrosis, while migration had been occurred in 6 patients $(30 \%)$ in the control group (group B), which was a statistically significant difference $(\mathrm{p}=0.0382)$. (Table 3$)$.

Table 3: Shows stone migration and stone free rate in both groups

\begin{tabular}{|c|c|c|c|}
\hline Group & $\begin{array}{c}\text { Total } \\
\text { number }\end{array}$ & $\begin{array}{c}\text { Stone } \\
\text { migration }\end{array}$ & $\begin{array}{c}\text { Stone free } \\
\text { rate }\end{array}$ \\
\hline Group A & 20 & $1(5 \%)$ & $19(95 \%)$ \\
\hline Group B & 20 & $6(30 \%)$ & $13(65 \%)$ \\
\hline
\end{tabular}

Although the mean operative time in our study was slightly longer in the group A ( $42 \pm 10$ minutes) than in the group B $(40 \pm 10$ minutes $)$, the difference was not significant $(\mathrm{p}=0.361)$.

No significant complications including ureteral perforation or avulsion had been occurred in either group. However, one patient in the (group A) had significant postoperative colicrequiring parenteral analgesics and one in the control group (group B) had fever postoperatively needed admission to the hospital and giving antibiotic and intravenous fluid.

The stone-free rate at 1-month follow up with ultrasound and CT scan was $95 \%$ in the (group A), and $65 \%$ in the (group B), and the difference between the two groups was statistically significant $(p=0.01711)$ as shown in table $4 \&$ figure 1 .

Table 4: stone migration \& stone free rate in both groups

\begin{tabular}{|c|c|c|c|}
\hline group & $\begin{array}{c}\text { Total } \\
\text { number }\end{array}$ & $\begin{array}{c}\text { Stone } \\
\text { migration }\end{array}$ & $\begin{array}{c}\text { Stone free } \\
\text { rate }\end{array}$ \\
\hline Group A & 20 & $1(5 \%)$ & $19(95 \%)$ \\
\hline Group B & 20 & $6(30 \%)$ & $13(65 \%)$ \\
\hline
\end{tabular}

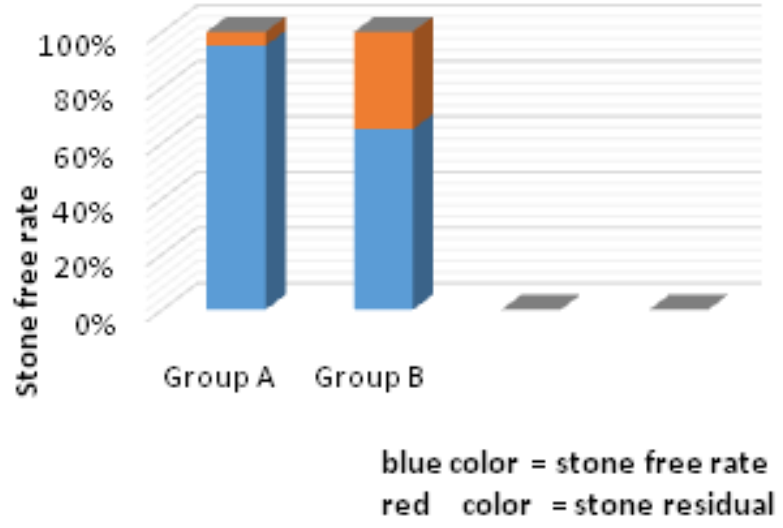

Figure 1: Stone free rate in both groups

\section{Discussion}

Intracorporeal lithotripsy modalities and stone removal devices have been created to facilitate the endoscopic management of ureteral stones.

These devices, along with improved technique, have resulted in stone-free rates often greater than $95 \%$ with low morbidity ${ }^{[12]}$.

Most of our patients were adults with age ranged from (1860 years), consisting of 28 males and 12 females. Regarding stone free rate, our study showed $95 \%$ stone free rate in group(A) compared with group(B) which showed $65 \%$ and the stone migration occurred in $5 \%$ in group (A) while it was $30 \%$ in group ( B), this had demonstrated the efficacy of lidocaine jelly in preventing upward stone migration and improving stone free rate, a finding which was comparable to other studies like Ali et al ${ }^{[13]}$ showed $100 \%$ stone free rate in 7 patients, Zehri et al ${ }^{[14]}$ study showed $96 \%$ stone free rate and $4 \%$ stone migration in 24 patients, and Sozen et al ${ }^{[15]}$ studyof 500 patients reported a stone-free and migration rate of $94.6 \%$ and $2 \%$, respectively.

Mohseni et al ${ }^{[16]}$ suggested that lubricating jelly instillation proximal to the ureteral stone during lithotripsy is an effective method of preventing retrograde stone displacement.

\section{Conclusion}

Instillation of $2 \%$ lidocaine jelly just proximal to the stone in the ureter before starting ureteroscopic guided Fragmentation of the stone using a pneumatic lithotripsy device is a simple and inexpensive option that cansignificantly reduce inadvertent stone migration and result in a higher stone free rate.

\section{Reference}

[1] Sierakowski R, Finlayson B, Lands RR, et al. The frequency of urolithiasis in hospital discharge diagnoses in the United States. Invest Urol 2005; 15438-441.441

[2] Bove P, Kaplan D, Dalrymple N, et al. Reexamining the value of hematuria testing in patients with acute flank pain. J Urol 1999; 162:685-7. 
[3] RasoolM,Tabassum SA, Mumta F, et al. Experience of uretroscopic pneumatic lithotripsy in management of lower and mid ureteric calculi. Annals 2008; vol. 14. No. 1

[4] JoelTeichman, MD. Smith's textbook of endourology, $2^{\text {nd }}$ ed. 2007; 37- 40.

[5] Piergiovanni M, Desgrandchamps F, Cochand-Priollet $\mathrm{B}$, et al. Ureteral and bladder lesions after ballistic, ultrasonic, electrohydraulic, or laser lithotripsy. J Endourol. 1994; 8: 293-299

[6] Bagley DH, Kuo RL, Zelter: an update on ureteroscopic instrumentation for treatment of uretrolithotomy .Curropinurol 2004; 14:99-106.

[7] Knispel HH, Klan R, Heicappell R and Miller K. Pneumatic lithotripsy applied through deflected working channel of miniureteroscope: results in 143 patients. J Endourol 1998;12: 513-515.

[8] Lee H, Ryan RT, Teichman JM, et al. Stone retropulsion during holmium:YAG lithotripsy. J Urol 2003; 169: 881-885.

[9] Delvecchio FC, Kuo RL and Preminger GM. Clinical efficacy of combined Lithoclast and Lithovac stone removal during ureteroscopy. J Urol 2000; 164: 40-42.

[10] Mirabile G, Phillips CK, Edelstein A, et al. Evaluation of a novel temperature-sensitive polymer for temporary ureteral occlusion. J Endourol2008; 22: 2357-2359.

[11] Pardalidis NP, Papatsoris AG and Kosmaoglou EV. Prevention of retrograde calculus migration with the Stone Cone. Urol Res 2005; 33: 61-64.

[12]Lam JS, Greene TD and Gupta M. Treatment of proximal ureteral calculi: Holmium YAG laser ureteral lithotripsy versus extracorporeal shock wave lithotripsy. J Urol. 2002; 167.

[13] Ali AA, Ali ZA, Halstead JC, Yousaf MW and Ewah P. A novel method to prevent retrograde displacement of ureteric calculi during intracorporeal lithotripsy. BJU Int 2004; 94: 441-442

[14]Zehri AA, Ather MH, Siddiqui KM and Sulaiman MN. A randomized clinical trial of lidocaine jelly for prevention of inadvertent retrograde stone migration during pneumatic lithotripsy of ureteral stone. Visit SAGE journals online. J Urol 2008; 180: 966-968

[15] Sozen S, Kupeli B, Tunc L, et al: Management of ureteral stones with pneumatic lithotripsy: report of 500 patients. J Endourol 2002; 17: 721-724.

[16] Mohseni MG, Arasteh S and Alizadeh F. Preventing retrograde stone displacement during pneumatic lithotripsy for ureteral calculi using lidocaine jelly. Urology 2006; 68: 505-507. 